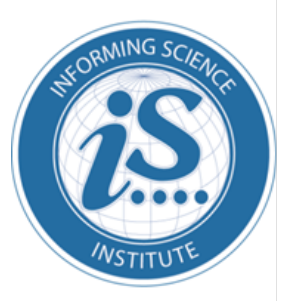

Proceedings of the Informing Science + Information Technology Education Conference

An Official Publication

of the Informing Science Institute

InformingScience.org

InformingScience.org/Publications

June 30 - July 4, 2019, Jerusalem, Israel

\title{
CLASSROOM IMPLEMENTATION OF INSTRUCTIONAL STRATEGIES AND TECHNIQUES THAT ARE BASED ON UNIVERSAL INSTRUCTIONAL DESIGN PRINCIPLES AND SUPPORT DIVERSITY
}

$\begin{array}{lll}\text { Mark Overgaard } & \begin{array}{l}\text { British Columbia Institute of Tech- } \\ \text { nology, Burnaby, Canada }\end{array} & \text { Mark_Overgaard@bcit.ca } \\ \text { Peter Fenrich* } & \begin{array}{l}\text { British Columbia Institute of Tech- } \\ \text { nology, Burnaby, Canada }\end{array} & \text { Peter_Fenrich@bcit.ca }\end{array}$

*Corresponding author

\begin{abstract}
Aim/Purpose This paper describes foundational principles of universal instructional design (UID), which is also known as universal design for learning, that support accessibility and inclusivity for a diverse population of students and discusses how these design principles and instructional strategies are being implemented in courses we instruct.
\end{abstract}

Background The goal of any instructor should be to ensure all students have their learning needs met. Unfortunately, this is complex. Each student is unique and can have individual learning needs and preferences. Consequently, it would likely be impossible to create instructional materials that address the specific learning needs and preferences of every individual. Principles of UID help to minimize this challenge. UID strategies should support deaf and hard of hearing individuals, students with a vision loss, learners who have difficulties staying focussed, weak readers, academically-weak students, students with low confidence, learners with high anxiety, individual learning preferences, and cultural minorities. UID principles should also lead to the creation of instructional materials that support cognitively-gifted students. The principles applied in our classroom, based on the principles of UID, helped to address these challenges that students have and foster a classroom environment that was conducive to supporting the diversity in our student population.

\footnotetext{
Accepting Editor: Eli Cohen | Received: December 12, 2018 | Revised: February 6, 2019 | Accepted: February 8, 2019.

Cite as: Overgaard, M., \& Fenrich, P. (2019). Classroom implementation of instructional strategies and techniques that are based on universal instructional design principles and support diversity. Proceedings of the Informing Science and Information Technology Education Conference, Jerusalem, Israel, pp. 249-256. Santa Rosa, CA: Informing Science Institute. https://doi.org/10.28945/4197
}

(CC BY-NC 4.0) This article is licensed to you under a Creative Commons Attribution-NonCommercial 4.0 International License. When you copy and redistribute this paper in full or in part, you need to provide proper attribution to it to ensure that others can later locate this work (and to ensure that others do not accuse you of plagiarism). You may (and we encourage you to) adapt, remix, transform, and build upon the material for any non-commercial purposes. This license does not permit you to use this material for commercial purposes. 
Methodology This is not applicable because this is a practical paper, not a research paper.

Contribution

This paper provides practical instructional strategies and techniques that can presumably help students with disabilities learn more effectively while also fostering a culture of inclusivity.

Findings There are no formal findings for this paper.

Recommendations Readers should consider applying the discussed instructional strategies and for Practitioners techniques to support their own students that have disabilities.

Recommendations Researchers should create instructional interventions for students with specific for Researchers disabilities and assess whether those interventions help students with that disability learn more effectively.

Impact on Society Although not proven by research on populations of individuals with disabilities, the presented instructional strategies and techniques are presumed to help students with a disability learn more effectively. The aim is for other instructors to create instructional materials with similar instructional strategies and techniques to enable accessibility and promote inclusivity for their diverse population of students.

Future Research From a practical perspective, instructors should apply the presented instructional strategies and techniques in their classrooms for their diverse population of students. In-class research could be done afterwards.

Keywords universal design for learning, diversity, inclusion

\section{INTRODUCTION}

What is our goal as instructors? Should we mainly teach for the brightest students, the majority of the students, or as many as is reasonably possible? Should the instructional strategies be efficient or effective? The instructor's goal, with respect to the materials discussed in this paper, was to design the materials to support as many varied learners as is reasonably possible. All learners, particularly students with cognitive and/or physical challenges, require instructional materials that specifically support them in the way they need to acquire knowledge. This paper discusses principles of universal instructional design (UID) and how those principles were applied in the classroom.

Ideally, the ultimate goal, of anybody who teaches, is to create learning materials that cater to the learning needs and preferences of each individual learner. Principles of UID can help all instructors effectively teach a diversity of learners. UID principles can be used to support deaf and hard of hearing individuals, students with a vision loss, learners who have difficulties staying focussed, weak readers, academically-weak students, learners with low confidence, students with high anxiety, cognitively-gifted students, individual learning preferences, and cultural minorities. Although not addressed here, there are other individuals with challenges, such as those on the autism spectrum, that also need learning interventions that specifically support them (Barnet, 2015).

\section{Principles of UNIVERSAL INSTRUCTIONAL DESIGN}

In the context of diversity and making learning materials accessible to a wide range of individuals, content should be designed so that it feels welcoming and inclusive, supports accessibility for the varied individuals who want to learn the content, ensures that there is alignment between the learning outcomes, presented material, and assessment techniques, enables classroom participation in a variety of ways, has effective instructional strategies that factor in the diversity of learners, and only has essential physical requirements required for performance (Coolidge, Doner, \& Robertson, 2015). 
UID principles strive for providing all learners multiple ways to be engaged, acquire information, and demonstrate the knowledge gained. The goal is for all learners to have their learning needs and preferences met, with some learners needing some accommodations to achieve that. Ideally, UID leads to the development of instructional materials that enable a wide range of learners to access and effectively learn from the content. However, from a practical perspective, it is not possible to perfectly support every student's learning needs. Fortunately, effective instructional design strategies and teaching techniques tend to support all individuals and some of the strategies and techniques inherently support a variety of diverse learning needs (Coolidge et al., 2015; Fenrich \& Carson, 2017; Fenrich, Carson, \& Overgaard, 2018a, 2018b).

\section{Design Process}

Since this paper discusses principles of UID and how those principles were applied in the classroom, a formal methodology was not followed. However, numerous things were done to help instructors create materials that aimed to help students with different cognitive and/or physical challenges learn more effectively. Literature was reviewed and interviews were conducted with experts in the field, the institute's Accessibility Services, instructors, and students to find out what instructional strategies support students with different disabilities. Based on historical information, the research was limited to the disabilities that the instructor's students were reasonably likely to have and what could be achieved given limits in the instructor's time and the timelines of the project. The instructor worked closely with an instructional designer. The instructional designer provided an instructional model to follow, called Gagnés Nine Events of Instruction, and discussed many learning theories with the instructor, and suggested numerous instructional strategies that support different learning theories, such as the constructivism theory.

The constructivism theory leads to instructional strategies that enable people to learn effectively. These strategies should enable learners to construct their knowledge based on their prior knowledge, beliefs, and experiences (Bradberry-Guest, 2011; Fenrich, 2015). Katzlberger (2006) stated, "Two pedagogical approaches that comply with the principles of constructivism are learning by doing and active learning. These strategies are based upon the idea that people learn best by doing things, not by being passive recipients of knowledge." Learning by doing and active learning lead learners to think about content and participate in their learning, which results in them constructing knowledge. This leads to higher levels of understanding as compared to passive approaches (Fenrich, 2015; Ruzhitskaya, 2012). As discussed below, some of the learning by doing and active learning instructional strategies and techniques included asking numerous questions, practice and feedback opportunities, group discussions, group work, varied activities, stories that students can relate concepts to, and think-pairshare activities.

Based on the theories, principles, and instructional strategies discussed and ongoing support of the instructional designer, the instructor created the materials within an iterative cycle of design and feedback.

The students referred to in this paper were piping trades students studying in a post-secondary institution in Burnaby, British Columbia, Canada.

\section{Practical Applications in THE Classroom}

Although an instructional model, such as Gagnés Nine Events of Instruction, can be used to create effective instructional materials (Fenrich, 2014), applying the model is not enough for some students. To enable all students to learn effectively, their cognitive and/or physical challenges need to be addressed. For the following challenges that students have, several principles and strategies were applied within the constraints of a full-time teaching load. These principles and strategies are described below. Fenrich et al. (2018a), Fenrich et al. (2018b), and Fenrich and Carson (2017) describe other principles and strategies that help students with varying challenges. 


\section{DEAF AND HARD OF HEARING STUDENTS}

For students with a mild hearing loss, a straightforward solution was to encourage those students to sit near the instructor to hear the instructor with greater clarity. Another strategy was to speak at a slower pace and pausing between sentences, allowing students the time to mentally process what they just heard or read. For students with a moderate to total hearing loss, close captioning was added to all of the video clips. As well, the PowerPoint ${ }^{\mathrm{TM}}$ images had descriptions included just below the image. This allowed the deaf and hard of hearing students another path to access the meaning of the image if they could not hear the instructor. We also provided extra time to work through the material.

\section{STUDENTS WITH A VISION LOSS}

Although uncommon in the trades due to safety concerns, there are occasionally students with a partial vision loss. We helped these students comprehend the content through different avenues. One avenue was to print their reading material in a much larger font. We also created PowerPoint slides that have a large enough font with colours that have high enough contrast to meet the web content accessibility guidelines (Henry, 2017). As described previously, all PowerPoint images had descriptions written below the images. As well, there were text descriptions of video. Lastly, the material was made available online. The digital text in the materials could be accessed with screen readers.

\section{STUDENTS WHO HAVE DIFFICULTIES STAYING FOCUSSED}

Given that trades students tend to be active all day at their jobs but have to sit still in the classroom, it is possible that some of those students will have difficulties staying focussed. As well, some students have medical conditions that make it difficult for them to stay focussed (Acevido, 2017). We employed many different strategies to combat this challenge.

One solution, which was intended to help students stay focussed, was to take a five minute break every 45 minutes. This allowed them time to move about. Another method used was to limit lecture portions of a class to a maximum of twenty minutes and have a participatory activity after the lecture. We also placed questions within the PowerPoint where students had to get into groups, discuss the question, and write down their answers. This gave them the opportunity to get up, walk around the classroom, and talk with multiple students. Another strategy was to put students into groups, give them an assignment, and then state that the group had a specified amount of time to complete the assignment, with the stipulation that they had to work outside of the classroom. This gave the students a different environment to work in during the day.

The material created moved seamlessly from one topic to another. Since there were no deviations from the instructional path, students were supported in only focusing on what was needed and were not distracted from content that did not address the learning outcomes.

\section{WEAKREADERS}

To support weak readers, a main strategy was to simplify the writing. If the text was written at the writer's language level, it may be too difficult for some readers to readily comprehend the content. The material we wrote had weak readers in mind. We broke large topics into a series of short paragraphs, most of which included a visual representation to help solidify the concepts. Sentences were short and to the point. The amount of text on a page or slide was kept to a small amount so as to not overwhelm the students with having too much text to work through at one time.

Instructors also explained concepts through telling stories. This helped students link the concept to a real-world scenario without having to read. We also enabled less dependence on text through visualization. An example of this was when teaching students to add and subtract fractions. We used eating 
pizza as an example. Visually, we showed the students how a pizza can be split up and fractions can be formed.

We also wrote the material using words that were easily comprehended. There was no need to use a complicated word when a simpler one served the purpose. The goal was not to make the writer look intelligent but rather to make the reader feel intelligent.

\section{ACADEMICALLY-WEAKSTUDENTS}

To support academically-weak students, we created a learning environment that allowed them time to mentally process the material. For example, many PowerPoint slides presented a question. Students were asked to think about the question and then work with another student to solve the problem. This gave all students an opportunity to think deeply about the material just presented. This thinking time was intended to give the academically-weak student time to "catch up". The thinking time was also intended to give the academically-strong students an opportunity to think deeply about the material. When academically-strong students explained concepts to weaker students, they needed to think deep enough to mentally process the content well enough to formulate an explanation. Hearing an alternative explanation can enable students to learn the material to a higher level (Vega \& Terada, 2012).

Another key strategy that was aimed to support academically-weak students was to present material in manageable amounts. For example, an entire electrical drawing for a furnace could make a student feel overwhelmed. To make the content manageable, the student was led through a series of questions that broke the drawing down into its components. After the components were covered, the student was guided through an exercise showing how all the components interlinked.

Another method that we used was to create short concise videos that explained the material. Students could review the videos before the content was presented in class so that they could have a head start on the concepts. These videos were placed on our learning management system. The students could watch the videos as many times as they needed and when they wanted.

The last thirty minutes of each session ended with a review of the session's material. The students worked in groups to summarize the concepts, formulas, and key points. The summaries the groups created were combined in a document that was handed back to everyone. This document became a resource to support studying.

Questions sets were also handed out as group projects where the group was marked as a whole. This created a safe environment where the students could benefit from supporting each other and learning from each other. This method, which was intended to support academically-weak students, seemed to result in higher grades. (This was not statistically verified.)

\section{STUDENTS WITH LOW CONFIDENCE}

Supporting students with low confidence started before the material was handed out or presented. To start with, the schedule was clearly laid out so that the students were oriented into what skills will be taught and when. As well, students were told that their success highly depended on their perseverance both in and out of class. It was hoped that this notion would start the learning process in a positive way.

To assist students with low confidence, material was created that gradually increased in complexity so that the students could experience many small successes. In contrast, if the content required large increments of learning before success could be achieved, some students might not have gained the confidence that they needed to be motivated to continue on (Keller, 1987).

Objectives were clearly stated and the following material directly supported the students in learning those skills. Summaries were provided at the end of each section. Also, materials ended with a set of 
questions that gradually guided the student through the concepts starting from the lowest skill level through to the more complex skills.

As described above for academically-weak students, students answered questions in groups. This activity was aimed to support students with low confidence.

\section{STUDENTS WITH HIGH ANXIETY}

Based on classroom observations, students with high anxiety tended to be successful in the classroom setting but, during formal exams, anxiety negatively impacted them. One strategy we implemented to help a student with high anxiety was to emphasize that failure was okay. Students who understood that failure was a part of the learning process seemed to have reduced anxiety and appeared to be more able to accept failure and look at it constructively.

We also ensured that each student had one-to-one time with the instructor to discuss their individual learning preferences and issues. If needed, the student and instructor devised a plan to help the student achieve the success they desired. This plan appeared to help reduce the anxiety that some students experienced. We hoped that this would show the student that the instructor cared about them and their personal success. This presumably created an environment where the student felt supported and that they would receive help as needed, which was intended to reduce their anxiety.

\section{ACADEMICALLY-GIFTED STUDENTS}

In the past, we had not particularly supported academically-gifted students because they could learn the material without much instructional support. However, there could be a risk that those students could become bored or not reach their potential (Newfound and Labrador Department of Education, 2013). With the aim to help stimulate academically-gifted students, group-based learning activities were created. These activities gave academically-gifted students the opportunity to explain concepts to students who were struggling. This was intended to help both the struggling and academically-gifted students solidify their understanding of the topics.

We included links to additional resources that all students, including the academically-gifted students, could access. Although these resources were not required materials, they allowed any student to study the topic to a greater depth.

As discussed earlier, limiting lectures to a maximum of twenty minutes and having a participatory activity after the lecture were aimed to engage the academically-gifted learners (as well as all of the other learners). Academically-gifted students appeared to be engaged with the embedded questions built into the PowerPoints.

Another strategy, for the academically-gifted students and the other studentss, was telling stories. Storytelling allowed students to process the material through a different cognitive path, therefore creating the potential of a greater depth of understanding (Walker, 2012).

\section{INDIVIDUAL LEARNING PREFERENCES}

There are many different learning preferences (Fenrich, 2014). Not all learners were taught in the exact manner that they preferred but content was created that transcended many different learning preferences.

We created content that was presented via lectures, PowerPoints, videos, and print. Different media were presented, including video, images, and text. Beyond teaching the theory, we also created material that allowed students to work through problems both in the classroom and in a lab setting that required practical skills. Students worked both individually and in groups. The material was also available on our learning management system. This gave students the opportunity to view this material not only in class but also in their own home or other places when they preferred. 
We also created assessment resources that helped students visualize the outcomes they were required to achieve. For example, during the soldering copper portion of the program, students must follow the specifications on a set of drawings to solder pieces of copper pipe together. Historically, we found that an issue that arose was that students had trouble visiualizing what they were creating. So, we provided the students with samples of finished projects that were models of what they were going to make. The students marked these projects with the marking guide and compared their marks to the instructor's marks. Therefore, before the students started the practical project, they knew what they needed to create and the standard by which it needed to be done. This was another pathway to learning the content.

All of the above variations presumably enabled each student the ability to learn the materials in some ways that they preferred.

\section{CULTURAL MINORITIES}

We created material that included references from many different cultures. We included names, food, sports, places, and other cultural aspects from around the world. This both allowed students to recognize the diversity in the classroom and enabled students from different cultures to identify with their particular background. Anecdotally, some students shared stories that related to their background.

\section{SUMMARY}

Instructional materials can be designed to support diversity. In general, designing materials based on an effective instructional model, such as Gagné's Nine Events of Instruction, supports all learners. However, more needs to be done to support the cognitive and/or physical challenges that some students have. To teach all students as effectively as is reasonably possible given a full teaching load, apply principles of UID that address ways to minimize the impact of the challenges that students have. Challenges students can face include being deaf and hard of hearing, having a vision loss, having difficulties staying focussed, being a weak reader, being academically weak, having low confidence, having high anxiety, being cognitively-gifted, having individual learning preferences, and being of a cultural minority.

\section{REFERENCES}

Acevido, J. (2017). Everyone can learn: Strategies for teaching adults with ADHD. Retrieved December 12, 2018, from https://globalaccess.bowvalleycollege.ca/blog/english-language-learning/everyone-can-learnstrategies-teaching-adults-adhd

Barnet, J. (2015). Using research-based strategies to teach algebraic problem solving skills to students with autism spectrum disorder. Retrieved December 12, 2018, from https://www.researchgate.net/publication/281443272 Using researchbased strategies to teach algebraic problem solving skills to students with autism spectrum disorde $\underline{\mathrm{r}}$

Bradberry-Guest, K. (2011). Effects of computer-based intervention on higher order thinking skills and implications for response to intervention (RTI) (Doctoral dissertation, Walden University, 2011).

Coolidge, A., Doner, S., \& Robertson, T. (2015). BC open textbook accessibility toolkit. Retrieved November 12, 2018, from http://opentextbc.ca/accessibilitytoolkit/

Fenrich, P. (2014). Practical principles of instructional design, media selection, and interface design with a focus on computerbased training / educational software. Santa Rosa, CA: Informing Science Press.

Fenrich, P. (2015). Evaluation of educational-software and paper-based resources for teaching logical-thinking skills to grade six and seven students (Doctoral dissertation, Open University Malaysia, 2015). 
Fenrich, P., \& Carson, T. (2017). Universal instructional design for accessibility and inclusivity: Supporting learners with challenges. Proceedings of the International Conference on Education and New Developments, June 24-26, 2017, Lisbon, Portugal.

Fenrich, P., Carson, T., \& Overgaard, M. (2018a). Comparing traditional learning materials with those created with instructional design and universal instructional design for learning attributes: The instructor's perspective. Proceedings of the International Conference on Education and New Developments, June 23-25, 2018, Budapest, Hungary.

Fenrich, P., Carson, T., \& Overgaard, M. (2018b). Comparing traditional learning materials with those created with instructional design and universal instructional design for learning attributes: The student's perspective. Proceedings of the Bulgarian Comparative Education Society XVII Annual International Conference, June 11-14, 2018, Varna, Bulgaria.

Henry, S. (2017). Web content accessibility guidelines. Retrieved November 12, 2018, from https://www.w3.org/WAI/intro/wcag

Katzlberger, T. (2006). Learning by teaching agents (Doctoral dissertation, Vanderbilt University, 2005).

Keller, J. (1987). Strategies for stimulating the motivation to learn. Performance and Instruction, 26(8), 1-7.

Newfound and Labrador Department of Education. (2013). Teaching students who are gifted and talented: A Handbook for teachers. Retrieved December 12, 2018, from https://www.ed.gov.nl.ca/edu/k12/studentsupportservices/publications/teachingstudentsgiftedtalented.p $\underline{\mathrm{df}}$

Ruzhitskaya, L. (2012). The effects of computer-supported inquiry-based learning methods and peer interaction on learning stellar parallax (Doctoral dissertation, University of Missouri-Columbia, 2011). https://doi.org/10.32469/10355/14226

Vega, V., \& Terada, Y. (2012). Research supports collaborative learning. Retrieved December 12, 2018, from https://www.edutopia.org/stw-collaborative-learning-research

Walker, S. (2012). Using stories to teach: How narrative structure helps students learn. Retrieved December 12, 2018, from https://www.scilearn.com/blog/using-stories-to-teach

\section{BIOGRAPHIES}

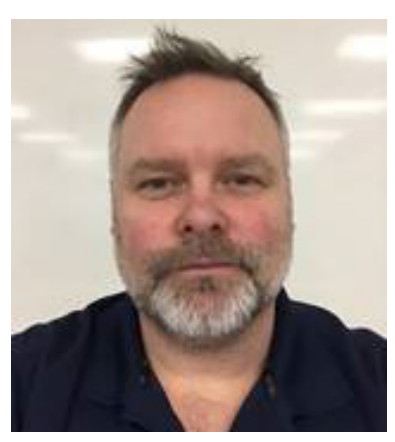

Mark Overgaard is a Piping instructor at the British Columbia Institute of Technology. He teaches plumbing apprentices through all four levels of their trades training. During their training, they receive instruction on both theory and practical applications in the plumbing field.

This is Mark's first conference abroad and the first time he has presented based on his work in the UID field.

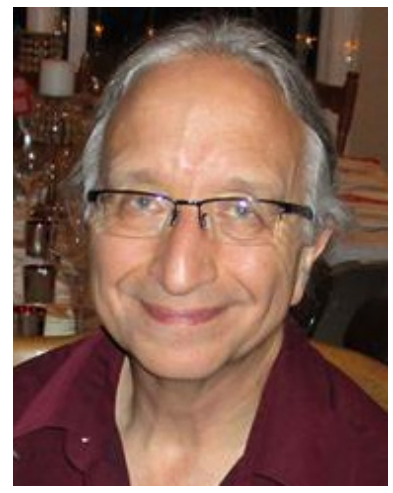

Peter Fenrich, an Instructional Development Consultant at the British Columbia Institute of Technology, designs online and face-to-face instructional materials, and supports instructor development, curriculum development, new program proposals, and program reviews. He also designs and creates innovative computer-based training and simulation software. His work has won international awards. Peter's book entitled, "Practical Principles of Instructional Design, Media Selection, and Interface Design with a Focus on Computer-based Training / Educational Software", provides practical information gained through years of experience. Peter also works internationally as a consultant and has earned a $\mathrm{PhD}$ in Education. 